Research Article

\title{
Dynamic Response of Multitower Suspension Bridge Deck Pavement under Random Vehicle Load
}

\author{
Chenchen Zhang, ${ }^{1,2}$ Leilei Chen $\mathbb{D}^{1,3}$ Gang Liu, ${ }^{3}$ and Zhendong Qian ${ }^{1,3}$ \\ ${ }^{1}$ Key Laboratory of Safety and Risk Management on Transport Infrastructures, Ministry of Transport, Southeast University, \\ Nanjing 210096, Jiangsu Province, China \\ ${ }^{2}$ China Iconic Technology Company Limited, Hefei 230000, Anhui Province, China \\ ${ }^{3}$ Intelligent Transportation System Research Center, Southeast University, Nanjing 210096, Jiangsu Province, China \\ Correspondence should be addressed to Leilei Chen; chenleilei@seu.edu.cn
}

Received 27 December 2020; Revised 25 January 2021; Accepted 1 February 2021; Published 12 February 2021

Academic Editor: Qinglin Guo

Copyright (c) 2021 Chenchen Zhang et al. This is an open access article distributed under the Creative Commons Attribution License, which permits unrestricted use, distribution, and reproduction in any medium, provided the original work is properly cited.

\begin{abstract}
Recently, the multitower suspension bridge has been widely used in long-span bridge construction. However, the dynamic response of the deck and pavement system of the multitower suspension bridge under random vehicle load is still not clear, which is of great significance to steel-bridge deck pavement (SBDP) design and construction. To reveal the mechanical mechanism of the steel-bridge deck pavement of the multitower suspension bridge under traffic load, this paper analyzed the mechanical response of the pavement based on case study through the multiscale numerical approach and experimental program. Firstly, considering the full-bridge effect of the multitower suspension bridge, the finite element model (FEM) of the SBDP composite structure was established to obtain key girder segments. Secondly, the influences of pavement layer, bending moment and torque, random traffic flow, and bridge structure on the stress of the girder segment were analyzed. Thirdly, the mechanical response of the pavement layer to the orthotropic plate under random vehicle load was studied. Finally, a full-scale model of the experimental program was established to verify the numerical results. Results show that (1) the pavement layer reduced the stress of the steel-box girder roof by about $10 \%$. In the case of adverse bending moment and torque, the longitudinal and transverse stresses of the pavement layer were mainly concentrated in the stress concentration area near the suspender. Under the action of the random vehicle flow, the stress response of the pavement layer was increased by 40\% compared with that under standard load. (2) Three-tower and twospan bridge structures have a great influence on the vertical deformation of the pavement layer under the action of vehicle load. Thus, the pavement material needs to have great deformation capacity. (3) The full-bridge effect has a significant influence on the longitudinal stress of the local orthotropic plate, but a small influence on the transverse stress. (4) There is a good correlation between the experimental measurement results of the full-size model and that of the numerical model. The research results can provide guidance for SBDP design and construction of the multitower suspension bridge.
\end{abstract}

\section{Introduction}

Multitower suspension bridge is a new type of bridge structure which has been widely used in recent years [1]. The continuous layout of multiple main spans is achieved by adding one or more main towers. The technical difficulty of scheme implementation and the overall project cost can be reduced [2]. However, the structure of a multitower suspension bridge is quite different from that of a traditional two-tower suspension bridge. The mechanical behavior of the multitower suspension bridge is more complicated. In addition, the steel-bridge deck pavement (SBDP) is placed directly above the bridge deck to protect the steel-bridge deck and share load, providing a riding surface that meets the driving requirements of the vehicle $[3,4]$. In recent years, with the continuous progress of deck pavement technology, design theory and construction technique of SBDP have increasingly matured. However, mechanical features are closely related to the steel-bridge deck system and are greatly influenced by the type of the bridge structure. The 
mechanical behavior of multitower suspension bridge SBDP still remains to be clarified.

Vehicle load is a critical external factor in the analysis of SBDP mechanical performance. Vehicle load is actually a fleet of vehicles distributed randomly in time and space. In addition, vehicle weight, speed, distance, axle weight, tire pressure, and other parameters have great randomness. Therefore, the concept of random vehicle load was proposed to study the fatigue damage of the bridge and its attached pavement. Early research studies focused on the statistical analysis of the random vehicle load spectrum [5]. At present, simulation of the random traffic flow is the main research direction $[6,7]$. The structural safety and the antifatigue performance of the bridge were verified by random vehicle load. However, there are few studies on the dynamic response of the deck and pavement system of the multitower suspension bridge under random vehicle load.

A lot of research has been done on the mechanical properties of asphalt concrete and SBDP [8-13]. At present, the research of SBDP mainly focuses on its mechanical properties. Zhao regarded the steel box girder for the longspan suspension bridge as the research object and then studied the calculation method of the load effect, fatiguedamage pavement failure mode, index system, calculation method, and reliability of the deck pavement design. Taking the steel box girder of the long-span suspension bridge as the research object, the calculation method of load effect, failure mode of the fatigue damage pavement, index system, calculation method, and reliability of the bridge deck pavement design were studied [14]. Wu et al. pointed out that with the increase of temperature, the stiffness of asphalt mixture SBDP decreased rapidly, which would lead to the rapid increase of stress on the orthogonal orthotropic steel-bridge deck [15]. Kainuma et al. used 3D FEM to analyze the stress and strain of orthotropic steel deck reinforced by bulb ribs [16]. A small-scale model of steel-bridge deck was established under static load to monitor the health of the bridge structure [17]. Taking Grota-Roweckiego Bridge as the example, the estimation of the residual fatigue life of the orthotropic bridge deck was studied [18]. Other experts have also studied the technology of mechanical performance of the asphalt pavement on the steel-bridge deck. As an effective research method, the multiscale model is widely used in the mechanical analysis of structures and bridges, but less in the analysis of the stress of different bridge deck pavements. Qian et al. puts forward the bridge-subsection pavement, a three-stage mechanical analysis technique of the bridge deck pavement, and applied it to the analysis of the bridge deck pavement of multiple bridges [19]. In order to extend the service life of SBDP, a long-life steel-bridge deck pavement (LLSBDP) was put forward [20]. The three-stage mechanical analysis technique was used to analyze the mechanical response law of SBDP considering bridge characteristics and uniformity [21]. Qian and Liu applied the stress-state transformation prestress of the first system to the local SBDP system and studied the influence of stress on the first system of steel-bridge deck on the stress of the SBDP layer [22]. Through large-scale model specimens, Zhang et al. demonstrated that setting the light concrete layer between the steel-bridge plate and asphalt pavement layer allowed stress to be equally distributed in the steel-bridge plate and improved the structural stiffness of the SBDP system [23]. Nevertheless, both structures can be simulated by a smaller model under vehicle load. The multiscale analysis approach is an important and useful tool to clarify the mechanical property of steel-bridge deck and pavement system.

In general, the multiscale analysis approach has been seldom used to study the influence of the bridge type on the mechanical behavior of SBDP, especially under random vehicle load. Therefore, this paper adopted the multiscale method to study the mechanical response of the whole bridge model under the action of random dynamic load through the case study. Taking the mechanical response of the whole bridge as the boundary condition, the critical girder segment model was established, and the influence of random dynamic load on the model was analyzed. Based on the girder segment model and in view of the effect of the multitower suspension bridge, the finite element refinement model of the steel-deck pavement composite structure was established. Finally, a local full-size bridge test model was established to verify the correctness of the finite element analysis results. The analysis results can provide guidance for the design and construction of the multitower suspension bridge and its SBDP part.

\section{Case Information}

2.1. Project Survey. Taizhou Bridge (TZB) is a highway bridge across the Yangtze River in China. The main bridge of the TZB is a three-tower and two-span continuous stiffening girder system. The side tower is made of the concrete structure, while the middle tower and stiffening girder are made of steel. The overall layout of the bridge is shown in Figure 1.

2.2. Load Model and Analysis Approach. The random vehicle load model was established, and the multiscale analysis approach was selected in this paper. A large-scale model was used to simulate the full-bridge model under working conditions, and a small-scale model was used to simulate the girder cross-section model and local detail model to study stress conditions. Furthermore, the SBDP synergy test model was designed to verify the results of the multiscale model in numerical simulation. The results of the hypothetical model were compared with those of the numerical model to study the cooperative working performance of the steel-bridge deck and pavement system.

2.2.1. Random Vehicle Load. Random vehicle load is greatly complex and random, containing the most unfavorable combination of load to match the actual working condition. It was applied to finite element analysis. The results lay a foundation for the establishment of a detailed SBDP system model with the full-bridge effect by numerical simulation and are also an important condition for the study of the SBDP system dynamic response under random vehicle load. 


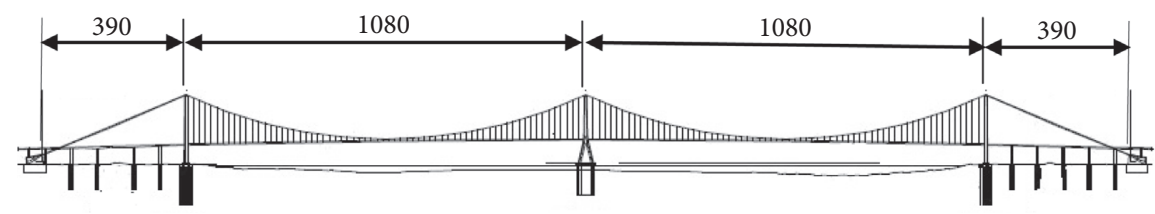

Figure 1: Overall layout of the Taizhou Yangtze river bridge (unit: M).

2.2.2. Multiscale Analysis Approach. In the current study of long-span bridge structures, such as multitower suspension bridges and cable-stayed bridges, the mid-girder model is usually used to simulate the full-bridge model. The bridge deck system was simulated in the girder element. The model is suitable for analyzing the dynamic and static characteristics of the bridge, and it reflects the distribution of internal forces and stress distribution along the main girder of the bridge. However, it is difficult to calculate the stress state of a specific girder cross-section. The cross-section of the largesize girder is usually simulated in the solid element or shell element. However, due to the limitation of the bridge size, it is difficult to accurately analyze the $\mathrm{cm}$-level detail structure. On this basis, in order to meet the requirements of different scale analysis, multiscale analysis provides a method to solve this problem by controlling boundary conditions and associating different scale models.

The full-bridge multiscale analysis method, key beam segments, and orthogonal anisotropic plates were adopted to analyze the mechanical properties of the pavement layer, as shown in Figure 2.

(1) Full-Bridge Model Analysis. The full-size bridge model was the first stage of multiscale analysis. Firstly, the mechanical responses such as deflection, axial force, bending moment, and torque of the whole structure were analyzed. Secondly, the most unfavorable position of the girder segment was identified. Finally, the displacement response of the boundary part for the local refinement model was studied.

(2) Subsection Model Analysis. As a boundary condition, the response of the full-bridge model to the corresponding location of the local model was established. In this case, mechanical responses of the most unfavorable girder under the external load were calculated. Then, the influence of pavement structural stiffness on the most unfavorable girder segment was analyzed.

(3) Finite Mixed-Element Model Analysis. On the basis of size, structure, and analysis target, the orthotropic composite structure refinement model was established. Stress and strain of the pavement system under the most unfavorable force were extracted as the boundary conditions of the submodel.

2.2.3. Test Model Design. According to the selection of model structures, model tests can be divided into two types: full-scale model and small-scale model. The model of the full-scale model test is in good agreement with the prototype of the test structure, which can effectively avoid the error in reverse calculation, and the test results are accurate and reliable. Therefore, the full- scale model was selected. The

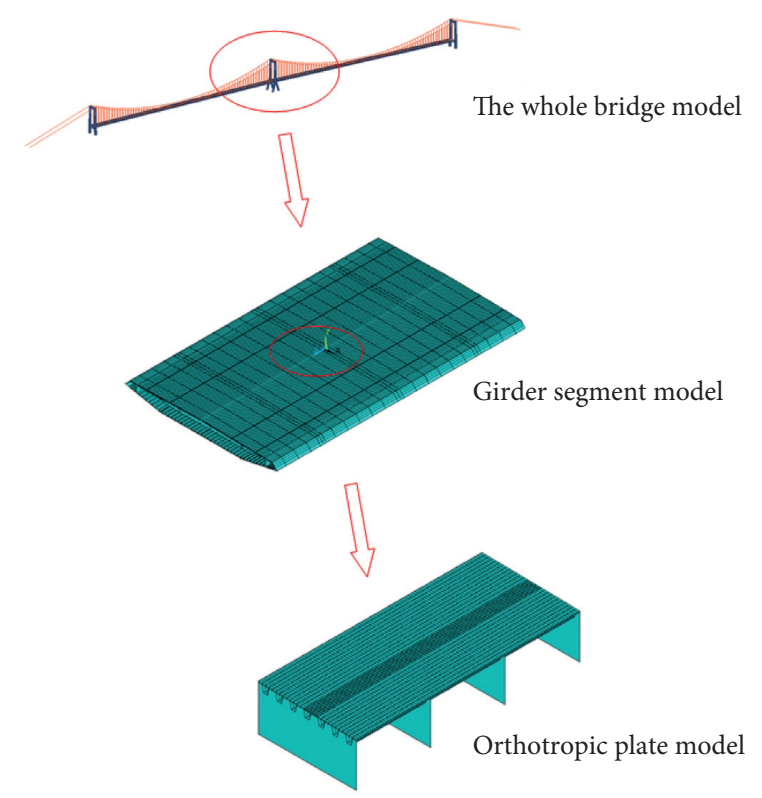

Figure 2: Schematic diagram of the three-stage analysis model.

idea of the design is shown in Figure 3. The main cable is consolidated at the anchorage, and the main cable is consolidated with the pylon. The boundary conditions of the FEM of the whole bridge are treated as follows: the pylon is set with vertical supports which can only slide along the bridge direction, and the pylon bottom is consolidated. The bridge design load is adopted as the load condition.

On the basis of analyzing the distribution characteristics of the SBDP stress response, the 3.2-meter-long longitudinal section and 2.4-meter-wide cross-section of the typical section were selected from the overall structure of the steel box girder. It was taken as the initial model of solid units under the synergistic effect of bridge deck and pavement, as shown in Figure 4.

\section{Multiscale Numerical Model}

3.1. Full-Bridge Model. The bending moment of the beam is the key to determine the most unfavorable beam. The deck pavement is constructed after the main bridge. Thus, mechanical analysis of the main bridge in the early stage should not be involved in the pavement, such as structural dead weight load and second-stage constant load. Main load originates from traffic load, temperature load, and wind load after completion of the bridge. Therefore, traffic load was taken as the main load, and vertical bending moment was taken as the main concern for internal forces for analysis in this paper. The most unfavorable girder segment of SBDP 


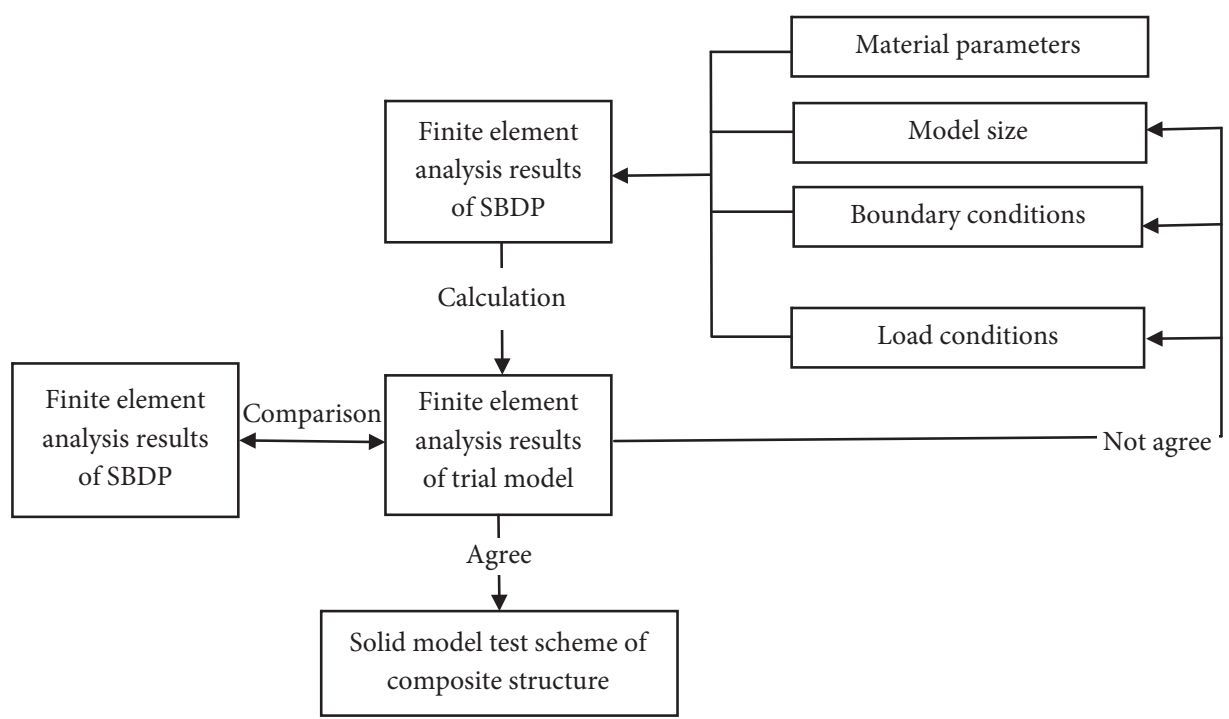

FIgURE 3: Design flow chart of the cooperative entity unit model for SBDP.

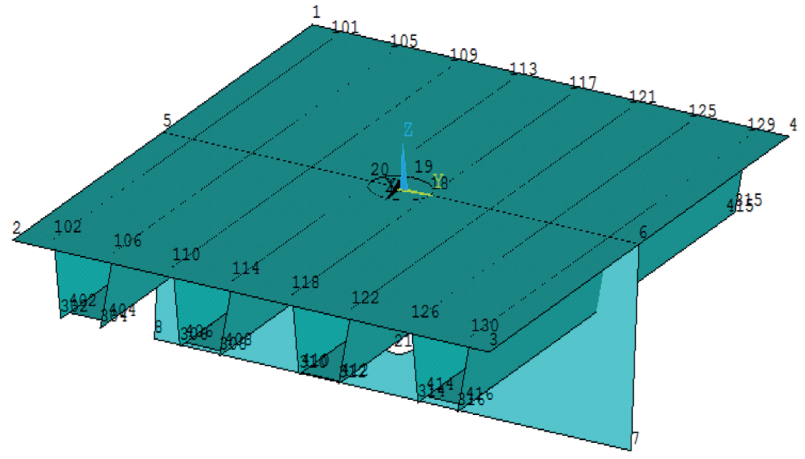

FIGURE 4: Three-dimensional FEM diagram of the initial model scheme of the solid element.

under live load was investigated. Analysis diagrams are shown in Figures 5 and 6.

The results showed that although the steel box girder of the middle tower was strengthened, the stress was still greater than that of the standard girder due to the excessive internal force. A 64-meter-long steel box girder segment in the mid-tower was identified as the most unfavorable. The length of the girder was $3.5 \mathrm{~m}$ relative to that of the steel box girder, which ensured the simulation accuracy of the middle section of the girder to its section. Then, the internal mechanical response on both sides of the girder was taken as the local boundary condition of the model.

\subsection{Subsection Model}

3.2.1. Finite Mixed Element Method. It is very important to accurately reflect the influence of the subsection model on the whole bridge so as to improve the accuracy of the model. The simulation of boundary conditions is the key to realize the overall effect of the bridge. To solve this problem, the boundary conditions of the girder segment model were simulated accurately by employing the finite mixed element method (FMEM), as shown in Figure 7.
3.2.2. Critical Girder Segment Model. There were four standard girder segments with $64 \mathrm{~m}$ in length and $39.1 \mathrm{~m}$ in width. It was simulated in the FMEM with ANSYS. The critical girder segment model is shown in Figure 8. Detailed structural size parameters of the steel box girder are shown in Table 1. There were two main materials in the subsection model. The other one was epoxy asphalt concrete, which is a temperature-sensitive material. Its elasticity modulus is a function of temperature, which decreases with the increase of temperature. Only normal temperature was considered, while modeling. Material parameters were selected on the basis of this temperature. The major material and structural parameters are listed in Tables 1 and 2 .

\subsection{Subelement Model}

3.3.1. Submodel Method. Submodel method, also known as the cutting boundary displacement method or specific boundary displacement method, is realized by the cutting local model based on the analysis of the coarse mesh model. Mesh refinement can be divided and calculated in the submodel. The submodel method is a secondary analysis process, the key of which is the boundary cutting and data transmission of the submodel. The submodel method is suitable for the simulation of a large bridge to transmit the full-bridge data from the girder segment model to the next model, such as the orthotropic plate model.

3.3.2. Orthotropic Composite System Model. In order to improve the accuracy of the model and obtain the detailed rules of local stress, the orthogonal anisotropic plate at the key stress position of SBDP was intercepted on the basis of analyzing the model of the main beam segment. Therefore, the influence of the full-bridge effect on the deck pavement is considered in the orthotropic plate model, which could conveniently reflect the stress of the pavement system and deck. In addition, the bridge deck, diaphragm, and stiffener 


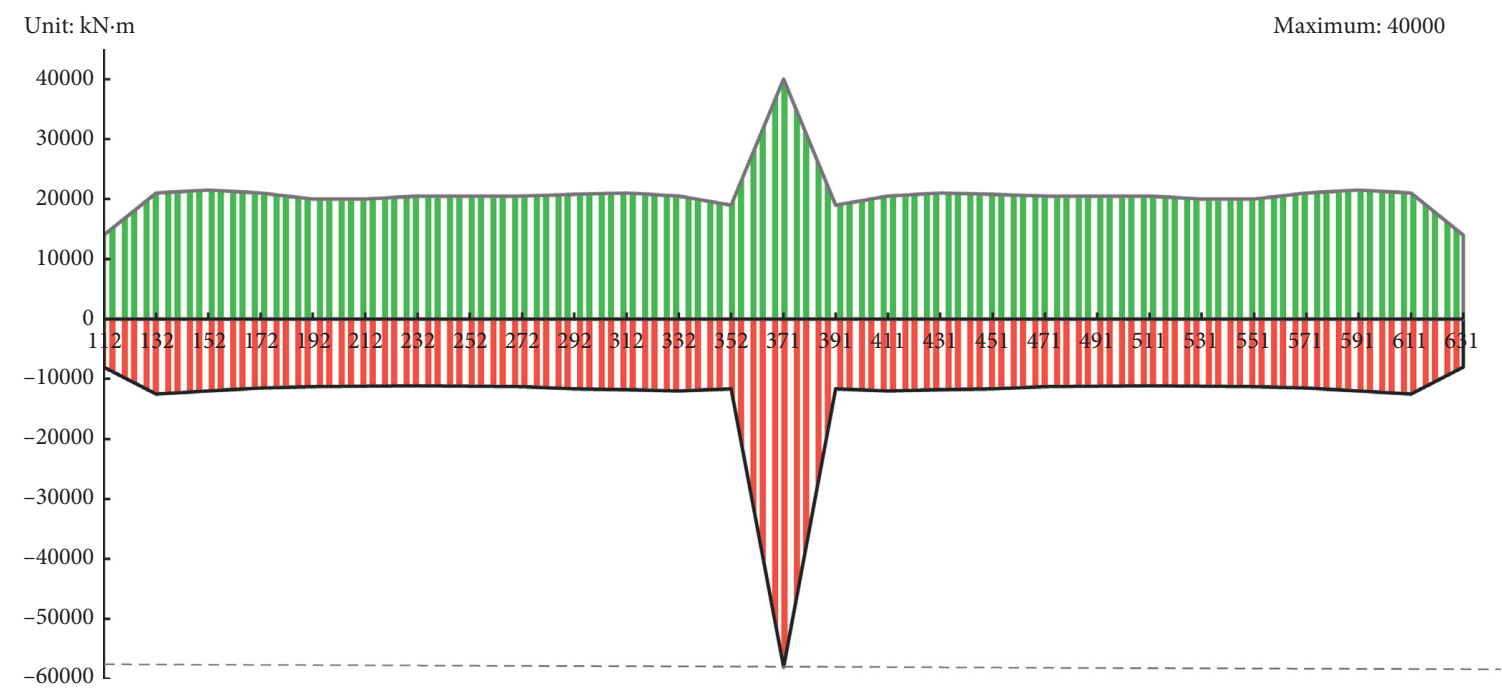

Figure 5: Bending moment envelope diagram of the girder under random traffic flow load.

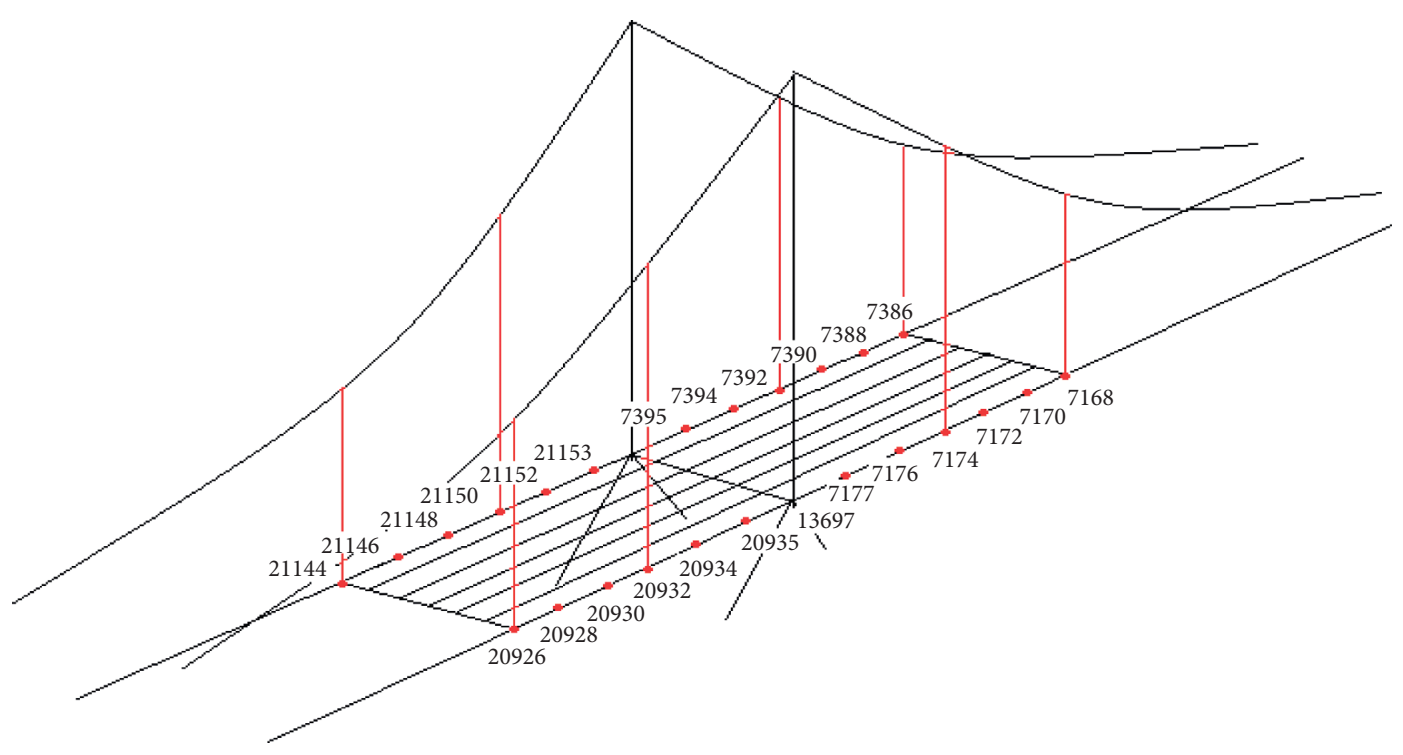

Figure 6: The most unfavorable beam diagram.

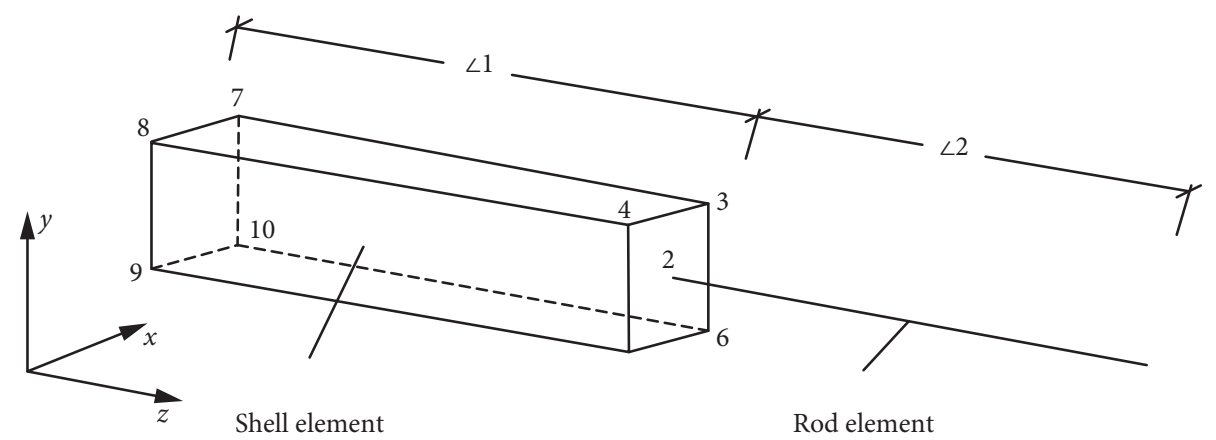

FIgURE 7: Diagram of the FMEM. 


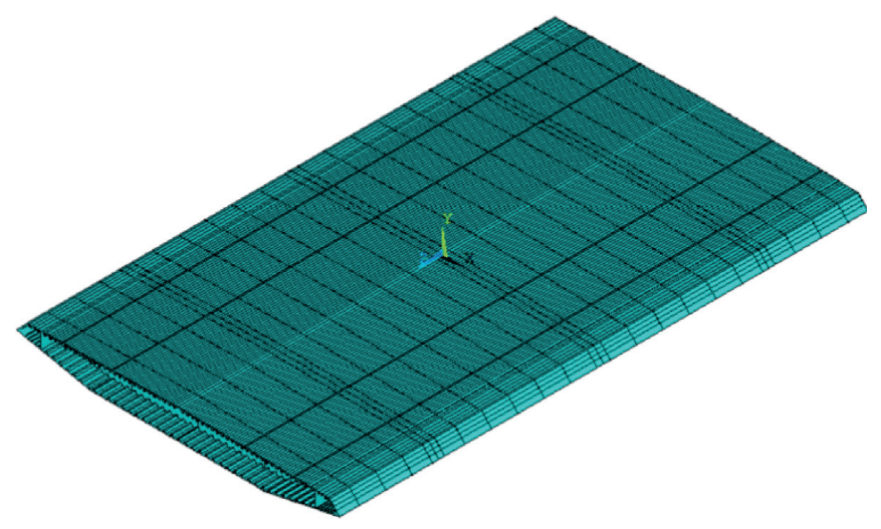

Figure 8: Critical segment model diagram.

TABLE 1: Material parameters used in the segment model.

\begin{tabular}{lccc}
\hline Steel & \multicolumn{3}{c}{ Epoxy asphalt concrete } \\
\hline Item & Value & Item & Value \\
\hline Elasticity modulus & $210000 \mathrm{MPa}$ & Elasticity modulus & $9000 \mathrm{MPa}$ \\
\hline Poisson's ratio & 0.3 & Poisson's ratio & 0.25 \\
\hline
\end{tabular}

were simulated by the shell element and the pavement layer by the solid element. The orthotropic bridge model is shown in Figure 9.

\subsection{Results' Analysis}

\subsubsection{Girder Segment Model}

(1) Effect of the Deck Pavement to the Steel Box Girder. The pavement layer actually contributes to the overall structural forces, especially anaphase loads such as vehicle load. The maximum vertical bending moment of standard middlelane load was set as the girder segment model to study the contribution of the pavement layer to the entire bridge structure under vehicle load. The internal force of the roof in the pavement layer is shown in Figure 10.

As can be seen from the nephogram, the pavement layer plays an auxiliary role in the internal force of the roof. The maximum tensile stress decreased by $10 \%$ from $51 \mathrm{MPa}$ to $44 \mathrm{MPa}$ when there was the pavement. In order to confirm its influence on roof stress, the middle part of the bridge close to the inner pavement and the two longitudinal strips close to the edge of the bridge outside the pavement were selected for stress comparison, as shown in Figure 11. It can be concluded that the pavement layer has a greater impact on the roof stress not only limited to the pavement area but also on the whole structure. Under the action of moving load, the influence of the pavement layer on the roof was obvious.

(2) Dynamic Random Vehicle Load. In the full-bridge model, the calculation results of bending moment and torque on both sides of the steel box girder under the random dynamic load of the vehicle were quite different from those under lane load. The calculation results of internal forces under random dynamic load were applied to both sides of the main girder section. Traffic load on the center of the girder was taken as uniform load, as shown in Figures 12 and 13. It can be seen that when random dynamic load of the vehicle was applied, the longitudinal and transverse tensile stress peak values of the steel-box girder under the maximum bending moment envelope value were $1.65 \mathrm{MPa}$ and $0.9 \mathrm{MPa}$, respectively, which increased by different extents compared with those under lane load. The longitudinal and transverse tensile stress peak value of the steel box girder under the maximum torque were $1.3 \mathrm{MPa}$ and $0.86 \mathrm{MPa}$, respectively, higher than those under lane load.

For comparison, different results under traffic load and lane load were recorded, as shown in Table 3, indicating that the results of vehicles under random dynamic load increased to different degrees compared with those under lane load. The overall growth rate was about $40 \%$, indicating that the simulation of increasing traffic volume was relatively lagging behind.

3.4.2. Orthotropic Steel Plate Deck Model. In order to analyze the influence of the characteristics of the whole bridge on the stress of the pavement layer, a high-rise analysis of the orthotropic steel plate was carried out without considering the influence of the whole bridge, that is, the conventional method was used for simulation without considering the initial boundary conditions. Dual-wheel load was transferred from middle span to diaphragm, as shown in Figures 14 and 15. The maximum longitudinal and transverse tensile stresses were $0.60 \mathrm{MPa}$ and $0.93 \mathrm{MPa}$, respectively, appearing on both sides of the upper deck under dual-wheel load. The maximum longitudinal and interlaminar transverse shear stresses between the pavement layer and top deck of the steel box girder were $0.60 \mathrm{MPa}$ and $1.24 \mathrm{MPa}$, respectively.

Considering the effect of the whole bridge, the results of the girder segment model were applied to the orthotropic plate model. The results of the orthotropic plate near mid-tower were selected to analyze the influence of the whole bridge on the high-rise model. As shown in Figures 16 and 17, the longitudinal tensile stress of the midspan pavement layer was about $0.14 \mathrm{MPa}$, and the maximum transverse tensile stress was $0.82 \mathrm{MPa}$ when considering the effect of the whole bridge. When wheel load acted on the edge of the diaphragm, the longitudinal tensile stress was about $0.62 \mathrm{MPa}$, and the maximum 
TABLE 2: Geometry dimensions of the subsection model.

\begin{tabular}{lccc}
\hline Project & Size $(\mathrm{mm})$ & Project & Size $(\mathrm{mm})$ \\
\hline Steel box girder roof thickness & 14 & Thickness of steel box girder bottom plate & 10 \\
Diaphragm spacing & 3200 & Bottom-plate trapezoidal stiffening rib thickness & 6 \\
Diaphragm thickness & 12 & Floor stiffener lower-mouth width & 400 \\
U-shaped stiffener thickness & 6 & Floor stiffener spacing & 850 \\
U-shaped rib opening width & 300 & Floor stiffener height & U-shaped rib height \\
U-shaped rib spacing & 600 & & 250 \\
\hline
\end{tabular}

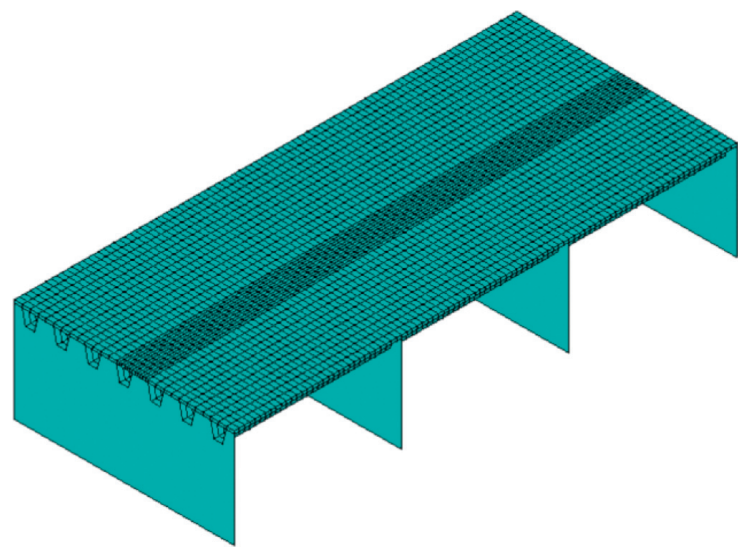

FIgURE 9: The orthotropic bridge model.

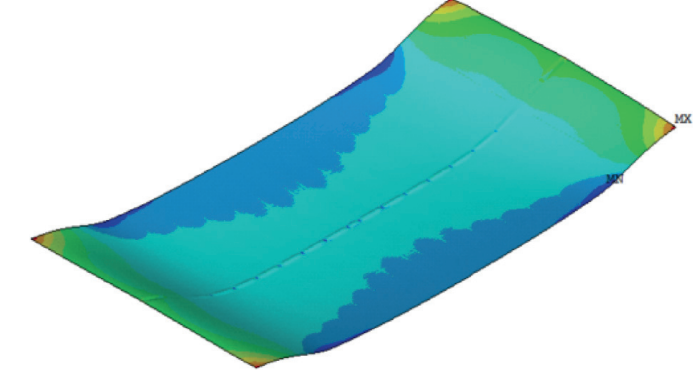

$\begin{array}{llllll}-0.744 E+07 & -966203 & -0.551 E+07 & 0.120 E+08 & & 0.184 E+08 \\ & & 0.249 E+08 & 0.314 E+08 & 0.379 E+08 & 0.443 E+08 \\ 0.508 E+08\end{array}$

(a)
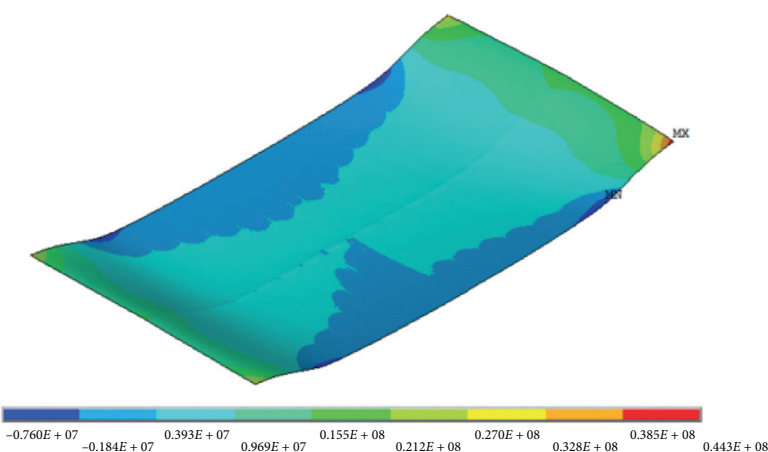

(b)

Figure 10: Nephogram of the steel-box girder roof along the bridge. (a) The steel box girder without the pavement player. (b) The steel box girder with the pavement player.

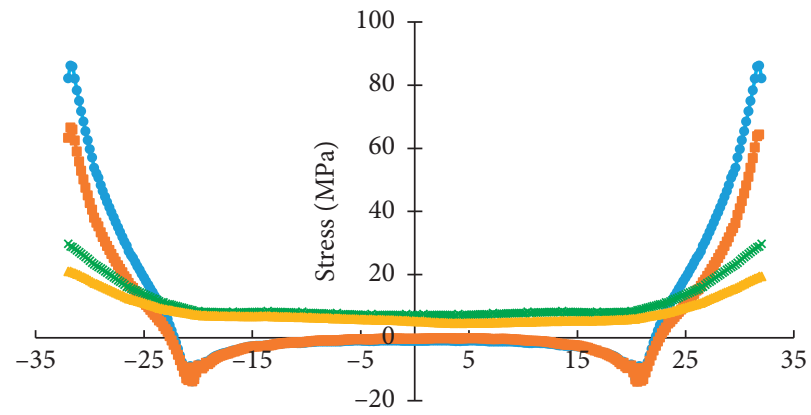

Distance along bridge $(\mathrm{m})$

$\rightarrow$ Outside without pavement - Outside with pavement

$\rightarrow$ Inside without pavement $\rightarrow$ Inside with pavement

Figure 11: Impact of the pavement layer to steel box girder force. 


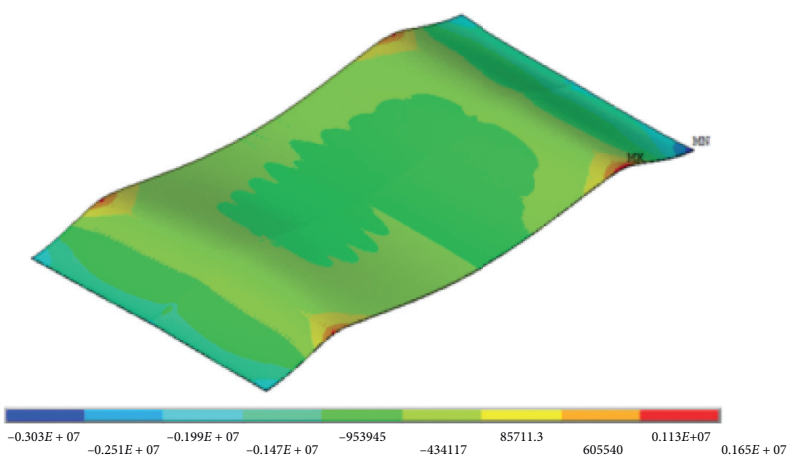

(a)

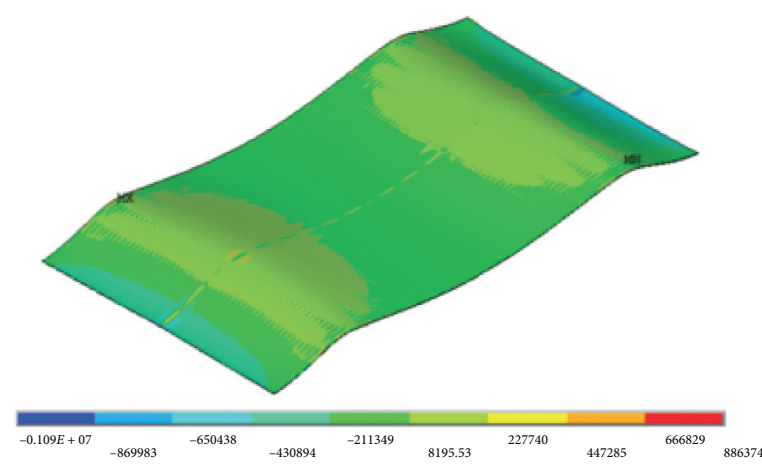

(b)

Figure 12: The stress diagram of the pavement layer under the most unfavorable bending moment of the random traffic flow. (a) The longitudinal stress diagram. (b) The transverse stress diagram.

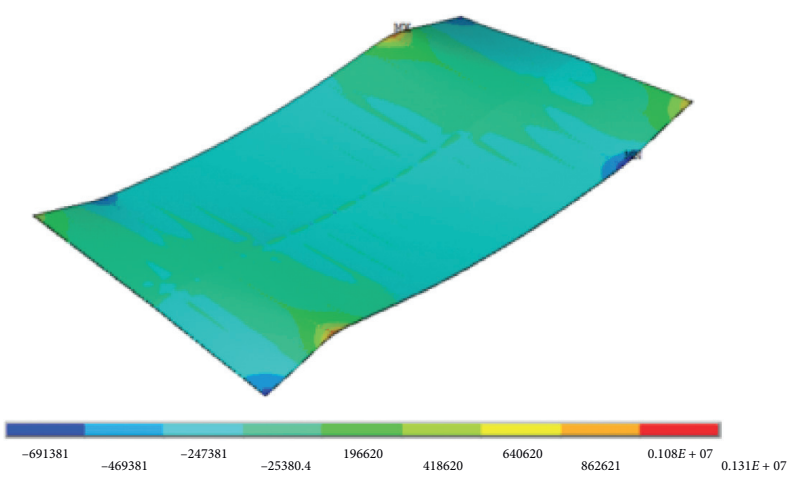

(a)

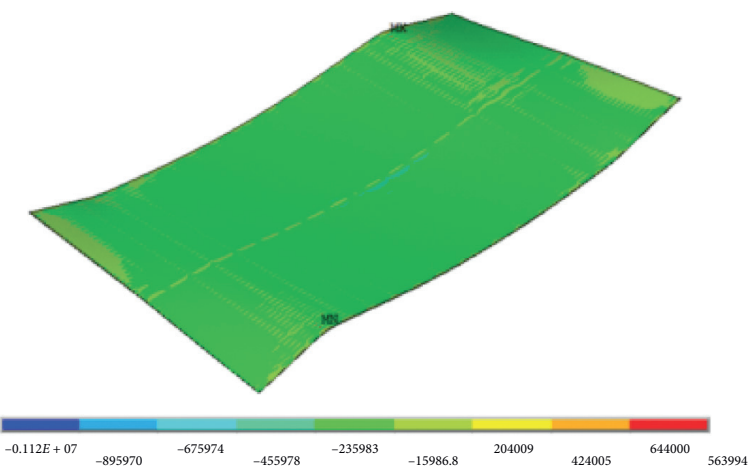

(b)

Figure 13: The stress diagram of the pavement layer under the most unfavorable torque of the random traffic flow. (a) The longitudinal stress diagram. (b) The transverse stress diagram.

TABLE 3: Comparison of random traffic flow and lane load results.

\begin{tabular}{lcccc}
\hline Moment & Stress & Load & Random traffic & Difference (\%) \\
\hline \multirow{3}{*}{ Bending moment } & Longitudinal tensile stress & 1.18 & 1.65 & 39.83 \\
& Transverse tensile stress & 0.65 & 0.89 & 36.92 \\
& Main longitudinal tensile stress & 0.26 & 0.3 & 15.38 \\
& Transverse main tensile stress & 0.38 & 0.54 & 42.11 \\
\hline \multirow{3}{*}{ Torque moment } & Longitudinal tensile stress & 0.97 & 1.31 & 35.05 \\
& Transverse tensile stress & 0.64 & 0.86 & 34.38 \\
& Main longitudinal tensile stress & 0.3 & 0.56 & 86.67 \\
\hline
\end{tabular}

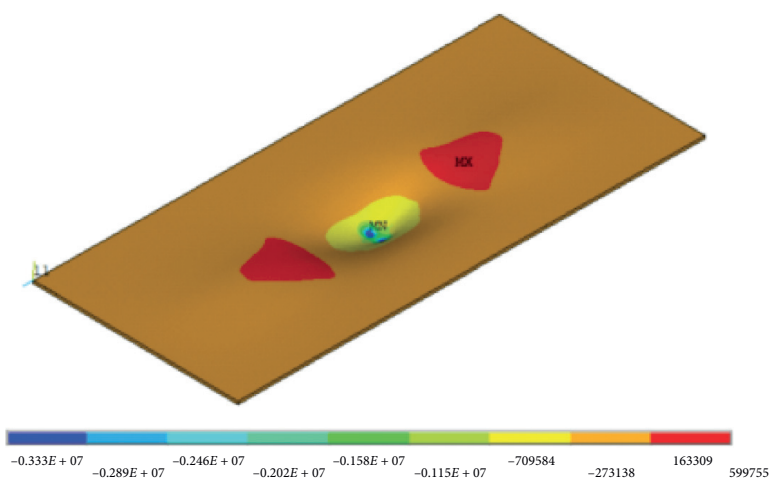

(a)

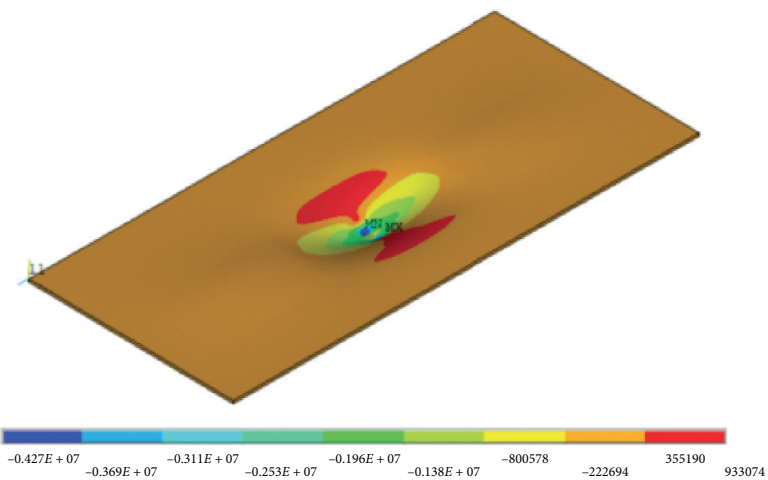

(b)

FIGURE 14: The stress diagram of the midspan pavement layer under dual-wheel load. (a) The longitudinal stress diagram. (b) The transverse stress diagram. 


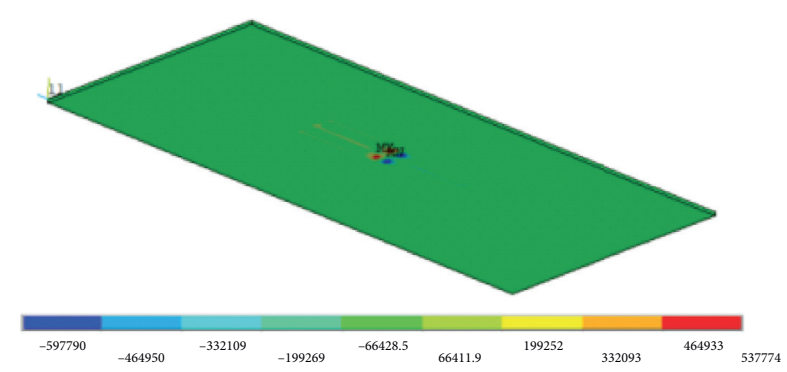

(a)

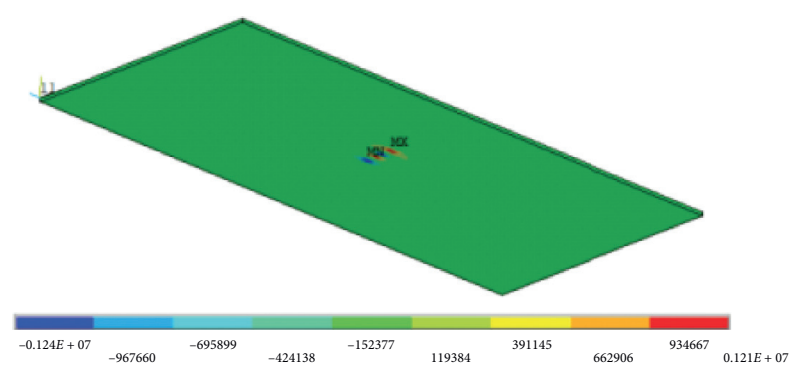

(b)

Figure 15: The shear stress diagram of the midspan pavement layer under dual-wheel load. (a) Interlaminar longitudinal shear stress. (b) Interlaminar transverse shear stress.

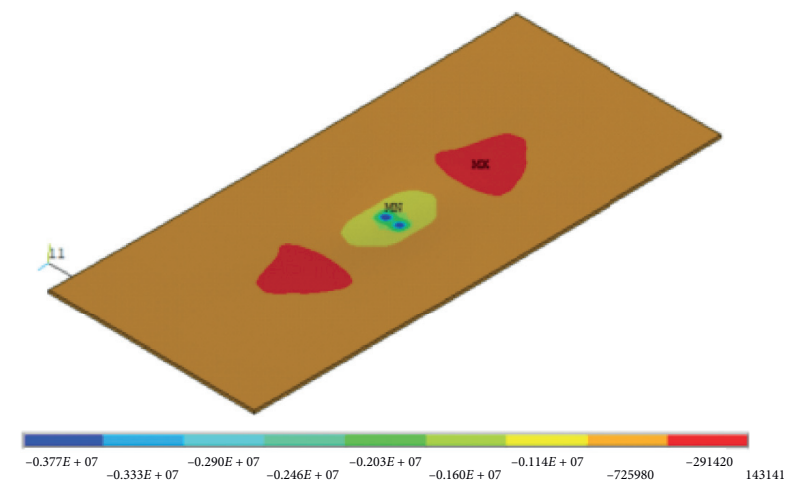

(a)

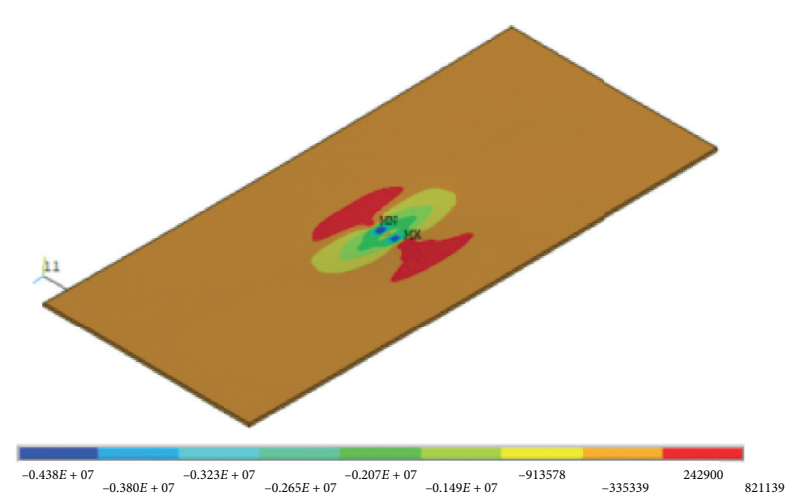

(b)

FIgURE 16: The stress distribution diagram of the midspan pavement under wheel load under full-bridge action. (a) The longitudinal stress diagram. (b) The transverse stress diagram.

transverse tensile stress was 1.46 MPa. The results showed that the influence of the whole bridge on the orthotropic plate stress was very obvious, especially on the longitudinal stress. The longitudinal stress caused by wheel load could be offset by selecting the area with large positive moment, which also indicated that it is the same as the position with large negative moment. However, transverse stress was not significantly affected. When wheel load acted on the middle span of diaphragm, the maximum transverse stress decreased from 0.93 MPa to 0.82 $\mathrm{MPa}$. In addition, when wheel load acted on the edge of diaphragm, the maximum transverse stress only decreased from $1.56 \mathrm{MPa}$ to $1.46 \mathrm{MPa}$.

\section{Experimental Program}

4.1. SBDP Synergy Test. In order to verify the results of numerical simulation, a full-scale model was first established in the experimental stage. In order to study the dynamic response of the bridge deck pavement system, the random vehicle load system and multichannel strain-displacement measurement system are needed. Several key points were set both on the bare deck and paved deck. The dynamic response of the deck pavement of the multitower suspension bridge under dynamic load was studied by the data collected by sensors. Then, the calculated results were compared with the simulation results.

4.1.1. The Establishment of the Full-Scale Model. According to the structural parameters and geometric dimensions of the full-size structural test model (Figure 18), box-type stud welding Q390 large thick steel plates were used. In addition, they were cut to the relevant dimensions required by the full-size test model. Then, they were processed and installed. The processing process and postinstallation model are shown in Figure 19.

4.1.2. Load System. In order to study the dynamic response of the bridge deck pavement, a load system which can realize the stochastic dynamic loading mode and has large load tonnage was required. Therefore, the large portal MTS hydraulic servo-loading system was selected as the load test system in this project.

4.1.3. Multichannel Strain Displacement Testing System. The length and width of the full-length structure are larger. The response characteristics of loads at different positions are also complex. In order to study the mechanical 


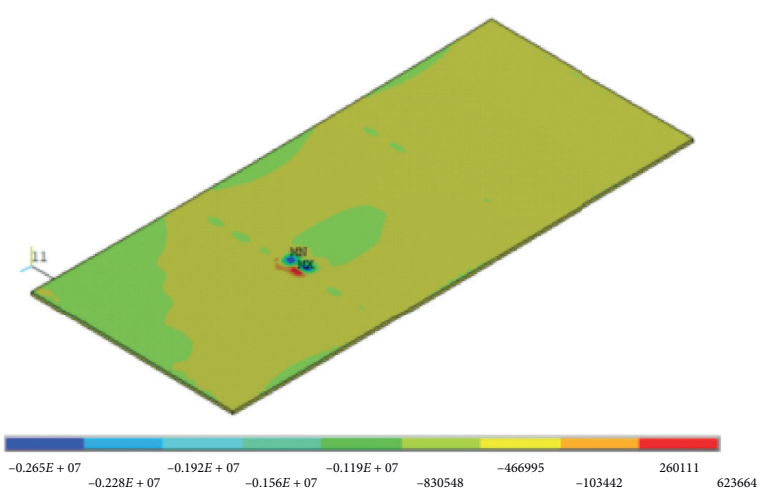

(a)

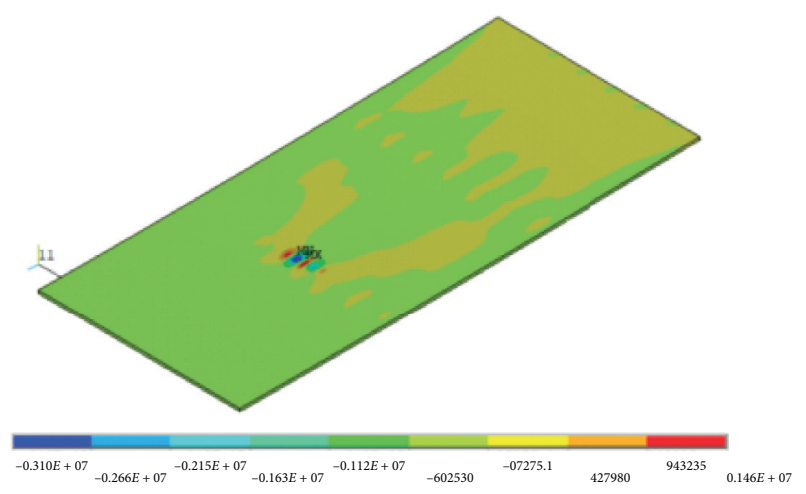

(b)

FIgURE 17: The shear stress distribution diagram of the midspan pavement under wheel load under full-bridge action. (a) Interlaminar longitudinal shear stress. (b) Interlaminar transverse shear stress.

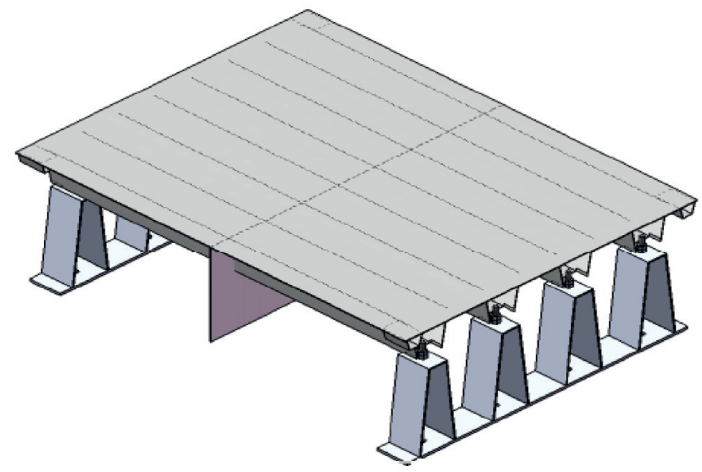

Figure 18: Effect diagram of the full-scale structure test model.

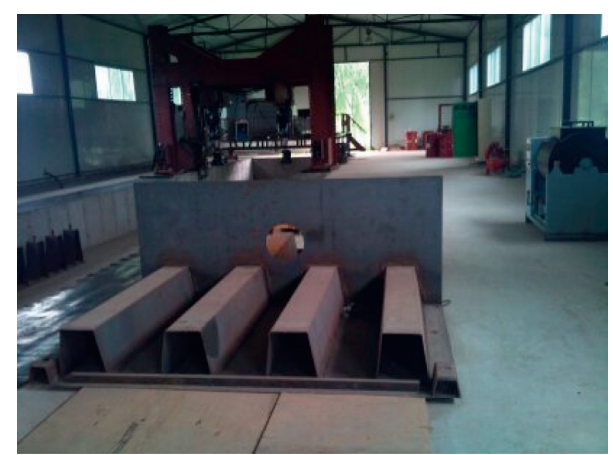

(a)

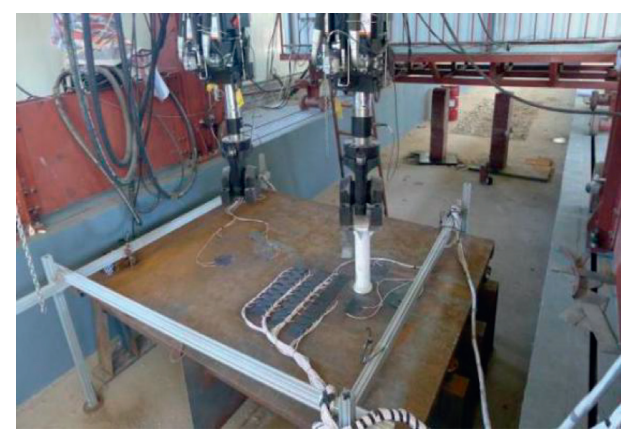

(b)

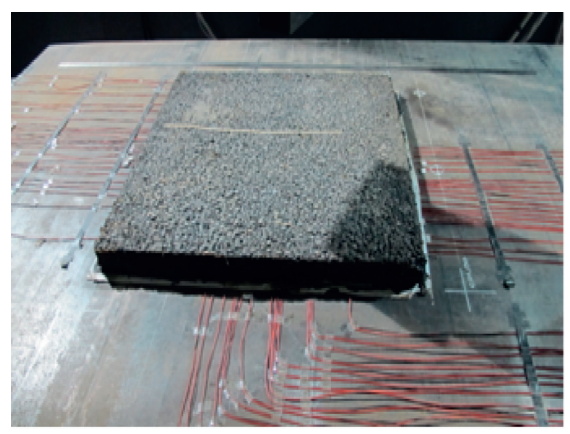

(c)

Figure 19: Processing and installation process of the full-scale structural test model with the SBDP synergistic effect. (a) The orthogonal anisotropic bridge-panel model. (b) The full-scale test model after completion. (c) The full-scale test model with the pavement. 


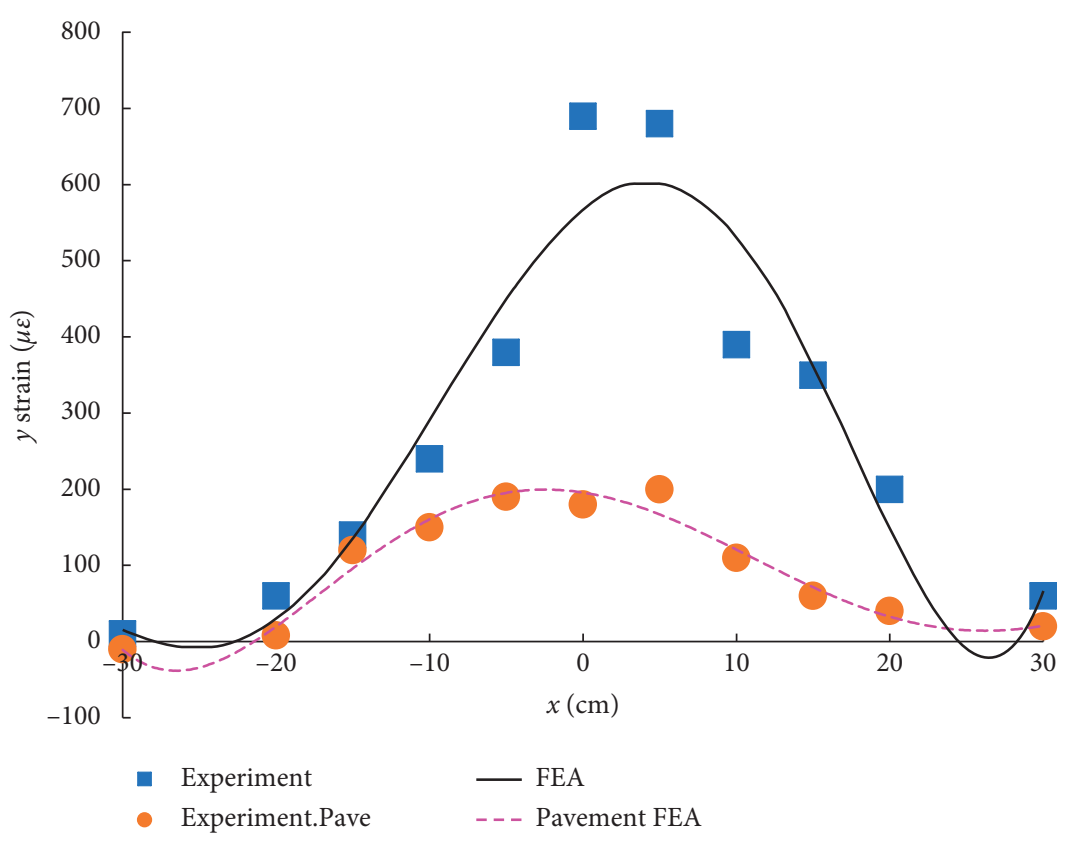

FIgUre 20: The strain at the top surface $(Y=+15 \mathrm{~cm})$ of the U-shaped stiffening rib-side plate.

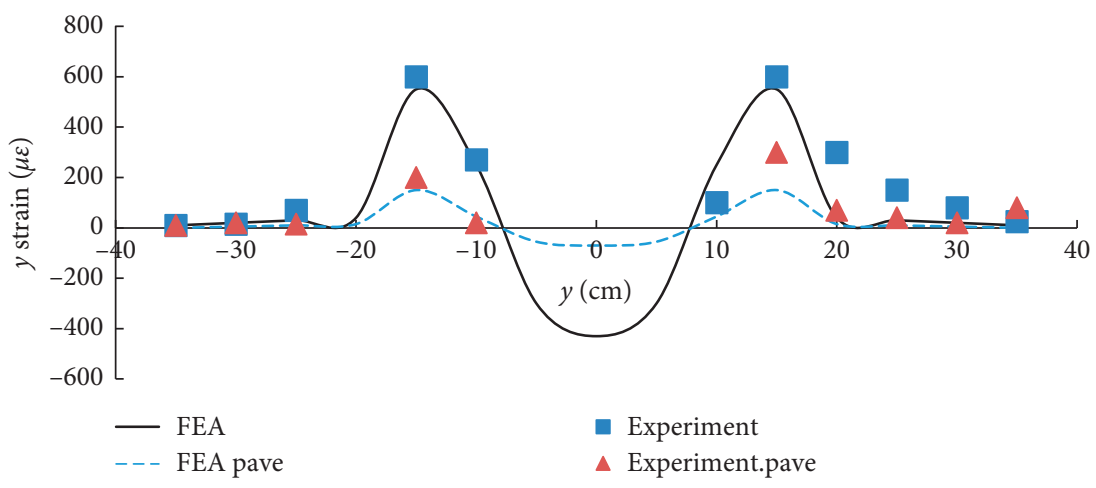

FIgURE 21: Strain at the transverse bridge section (i.e., $X=0 \mathrm{~cm}$ position) passing through the load center point.

characteristic points and sections of the full-scale model, a test system that could collect the load response, stress, strain, and displacement of different measuring points was needed.

\subsection{Comparative Analysis of Test and Numerical Simulations.} In order to study the multispan suspension characteristics of the deck pavement, the mechanical response of bare steelbox girder deck under the action of dynamic load was firstly studied. On this basis, the mechanical response characteristics of the composite structure of the steel-box girder bridge with the deck pavement under the action of dynamic load were studied. In the study, strains of several characteristic points were compared and analyzed, as shown in Figures 20 and 21 .
It can be seen that the measured value of the steel-bridge deck pavement with the pavement layer was close to the calculated value of the finite element model, and the overall trend and rule were consistent, but there were certain deviations. According to the above calculation and analysis, the steel plate thickness and the constraint conditions of diaphragm exert a very important influence on the mechanical response of the whole model.

Due to the steel plate processing and welding used in the unit solid structure model, the thickness of the steel plate was not uniform, and the size deviation of different positions was large. Therefore, the unit entity structure model size and the thickness of the steel plate were measured. And, the elastic modulus of steel was tested. On the basis of the finite element numerical model, the related parameters were processed and further modified. The modification contents and methods are as follows: 


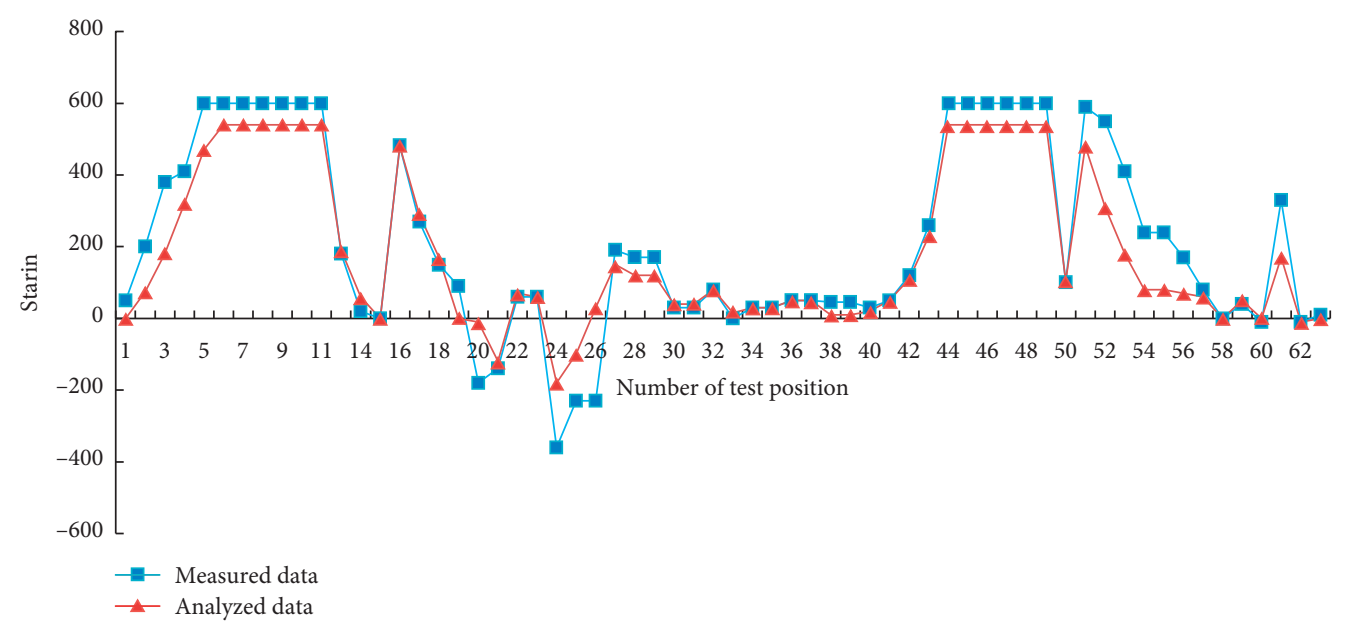

FIGURE 22: Comparison of measured and finite element numerical calculation results (strain).

(1) The measured structural dimensions and thickness of the steel deck element solid model were substituted into the finite element numerical model

(2) The elastic modulus of the processed steel plate was measured

(3) Boundary conditions with vertical constraints were adopted instead of the consolidation support

After the above modification of the finite element numerical model, a comparative analysis was conducted between the strain measured under the static load of the bare slab and the finite element numerical calculation results, as shown in Figure 22.

As can be seen from Figure 22, after the modification of the finite element numerical model, the experimental measured results of the full-size model had a very good correlation with the calculation results of the finite element numerical model. The variation trend of the data was completely consistent with the strain direction, and the numerical values were also very close.

\section{Conclusion and Discussion}

In this paper, the mechanical response of SBDP of the multitower suspension bridge under moving load was analyzed by multiscale numerical and experimental methods. Considering the full-bridge effect of the multitower-span suspension bridge, the three-stage finite element refinement model of the steel-bridge deck pavement composite structure was studied. Additionally, the fullscale experimental model was established to verify the simulation results. From the above analysis, the following conclusions can be drawn:

(1) The pavement layer contributes to the stress of the steel box girder. In the most unfavorable model of the bridge, the pavement layer reduces the maximum stress by about $10 \%$.

(2) The mechanical response of the pavement layer under the random traffic flow is generally $40 \%$ larger than that under the standard load. It can be seen that the actual moving load is underestimated in the standard as the volume of traffic increases.

(3) Three-tower and two-span bridge structures have a great influence on the vertical deformation of the pavement under vehicle load. Therefore, the pavement material should have great deformation capacity.

(4) The full-bridge effect also has an obvious influence on the stress of the local orthotropic plate, especially the longitudinal stress, but has little influence on the transverse stress.

(5) The experimental measured results of the full-size model have a very good correlation with the calculation results of the finite element numerical model, which demonstrates the validity of multiscale numerical results.

The research results can provide guidance for the design and construction of SBDP in a multitower suspension bridge.

\section{Data Availability}

The data used to support the findings of this study are included within this article.

\section{Conflicts of Interest}

The authors declare that there are no conflicts of interest regarding the publication of this paper. 


\section{Acknowledgments}

This work was supported by Natural Science Foundation of Jiangsu (Grant no. BK20191267) and Fundamental Research Funds for the Central Universities (Grant no. 2242020R40094).

\section{References}

[1] J. Cheng, $\mathrm{H}$. Xu, and M. Xu, "Study on midtower longitudinal stiffness of three-tower four-span suspension bridges with steel truss girders," Structural Engineering and Mechanics, vol. 73, no. 6, pp. 641-649, 2020.

[2] S. B. Chai, R. C. Xiao, X. L. Wang, and X. Ren, "Analytic method for calculating anti-slip safety factor between main cable and saddle in multi-tower suspension bridge," China Journal of Highway and Transport, vol. 29, no. 4, pp. 59-66, 2016.

[3] W. Huang, "Integrated design procedure for epoxy asphalt concrete-based wearing surface on long-span orthotropic steel deck bridges," Journal of Materials in Civil Engineering, vol. 28, no. 5, Article ID 04015189, 2016.

[4] L. L. Chen, G. Liu, Z. D. Qian, and X. F. Zhang, "Determination of allowable rutting depth based on driving safety analysis," Journal of Transportation Engineering Part B Pavements, vol. 146, no. 2, Article ID 04020023, 2020.

[5] S. R. Chen and J. Wu, "Dynamic performance simulation of long-span bridge under combined loads of stochastic traffic and wind," Journal of Bridge Engineering, vol. 15, no. 3, pp. 219-230, 2010.

[6] J. M. Cai, "Better fitting for distribution of vehicles flow on road segment of city," Journal of Shanghai University of Engineering Science, vol. 20, no. 2, pp. 100-103, 2006.

[7] T. Wang, W. Han, F. Yang, and W. Kong, "Wind-vehicle-bridge coupled vibration analysis based on random traffic flow simulation," Journal of Traffic and Transportation Engineering (English Edition), vol. 1, no. 4, pp. 293-308, 2014.

[8] P. F. Liu, J. Hu, H. Wang, F. G. Canon, D. Wang, and M. Oeser, "Influence of temperature on the mechanical response of asphalt mixtures using microstructural analysis and finite-element simulations," Journal of Materials in Civil Engineering, vol. 30, no. 12, Article ID 04018327, 2018.

[9] P. F. Liu, H. N. Xu, D. W. Wang, C. Schulze, and M. Oeser, "Comparison of mechanical responses of asphalt mixtures manufactured by different compaction methods," Construction and Building Materials, vol. 162, no. 2018, pp. 765-780, 2019.

[10] P. F. Liu, Q. Zhao, H. L. Yang et al., "Numerical study on influence of piezoelectric energy harvester on asphalt pavement structural responses," Journal of Materials in Civil Engineering, vol. 31, no. 3, Article ID 04019008, 2019.

[11] Q. H. Huang, Z. D. Qian, L. L. Chen, and M. Zhang, "Evaluation of epoxy asphalt rubber with silane coupling agent used as tack coat for seasonally frozen orthotropic steel bridge decks," Construction and Building Materials, vol. 241, no. 30, Article ID 117957, 2020.

[12] Q. H. Huang, Z. D. Qian, J. Hu, and D. Zheng, "Investigation on the properties of aggregate-mastic interfacial transition zones (itzs) in asphalt mixture containing recycled concrete aggregate," Construction and Building Materials, vol. 269, no. 1, Article ID 121257, 2021.

[13] Q. H. Huang, Z. D. Qian, Y. M. Yang, and D. Zheng, "Investigation of warm mix epoxy asphalt compaction with gyratory compactor and charge coupled photoelectric imaging," Construction and Building Materials, vol. 271, no. 15, Article ID 121506, 2021.

[14] F. J. Zhao, "The research on design method for steel deck asphalt pavement on large-pan steel box beam bridges", $\mathrm{PhD}$ Dissertation, Hunan University, Changsha, China, 2012.

[15] C. Wu, H. Y. Liu, Z. H. Zhang, and Y. Sun, "Influence of pavements temperature on fatigue life of orthotropic deck of steel bridge," Journal of Tongji University (Natural Science), vol. 41, no. 8, pp. 1213-1218, 2013.

[16] S. Kainuma, Y.-S. Jeong, J.-H. Ahn, T. Yamagami, and S. Tsukamoto, "Behavior and stress of orthotropic deck with bulb rib by surface corrosion," Journal of Constructional Steel Research, vol. 113, pp. 135-145, 2015.

[17] S. Iglouli, N. Boumechra, and K. Hamdaoui, "Damage or change detection in a small scale model of steel bridge deck under static loading by extensometery," IOP Conference Series: Materials Science and Engineering, vol. 419, Article ID 012024, 2018.

[18] A. Kasprzak and A. Berger, "Strengthening and widening of steel single box girder bridge in Warsaw," Structural Engineering International, vol. 29, no. 4, pp. 533-536, 2019.

[19] Z. D. Qian, W. Huang, X. Du, and L. Yun, "Research on effects of shape of long-span cable-supported bridge on mechanical analysis of surfacing under vehicular load," Strategic Study of CAE, vol. 8, no. 9, pp. 35-41, 2006.

[20] L. L. Chen, Z. D. Qian, D. X. Chen, and Y. Wei, "Feasibility evaluation of a long-life asphalt pavement for steel bridge deck," Advances in Civil Engineering, vol. 2020, Article ID 5890945, 8 pages, 2020.

[21] L. L. Chen, Z. D. Qian, and C. Zhang, "Bridge structure effect in the crack analysis of the steel deck pavement," in Proceedings of the Geo-Hubei 2014 International Conference on Sustainable Infrastructure, Yichang Hubei, China, 2014.

[22] Z. D. Qian and Y. Liu, "Mechanical analysis of waterproof bonding layer on steel bridge deck under bridge-temperature-load coupling effect," Journal of Southeast University (Natural Science Edition), vol. 42, no. 4, pp. 729-733, 2012.

[23] J. P. Zhang, S. W. Liu, and Y. J. Liu, "Large-scale model test on mechanics characteristics of composite pavement of steel bridge deck," Journal of Tongji University, vol. 41, no. 12, pp. 1837-1842, 2013. 